\title{
$\beta$-elemene reverses the drug resistance of lung cancer A549/DDP cells via the mitochondrial apoptosis pathway
}

\author{
CHENG-CAI YAO ${ }^{1,2}$, YUAN-RONG TU ${ }^{1}$, JIE JIANG ${ }^{3}$, SHENG-FANG YE ${ }^{4}$, HAO-XIN DU ${ }^{2}$ and YI ZHANG ${ }^{2}$ \\ ${ }^{1}$ Department of Thoracic Surgery, The First Affiliated Hospital of Fujian Medical University, Fuzhou, Fujian 355000; \\ ${ }^{2}$ Department of Thoracic Surgery, Xiamen Traditional Chinese Medicine (TCM) Hospital Affiliated to \\ Fujian University of TCM, Xiamen 361009; ${ }^{3}$ Department of Thoracic Surgery, The First Affiliated Hospital of \\ Xiamen University, Xiamen 361001; ${ }^{4}$ College of Molecular Biology and Material \\ of Xiamen University, Xiamen 361000, P.R. China
}

Received January 5, 2014; Accepted February 26, 2014

DOI: 10.3892/or.2014.3083

\begin{abstract}
ELE) is a new anticancer drug extracted from Curcuma zedoaria Roscoe and has been widely used to treat malignant tumors. Recent studies have demonstrated that $\beta$-ELE reverses the drug resistance of tumor cells. To explore the possible mechanisms of action of $\beta$-ELE, we investigated its effects on cisplatin-resistant human lung adenocarcinoma A549/DDP cells. The effects of $\beta$-ELE on the growth of A549/DDP cells in vitro were determined by MTT assay. Apoptosis was assessed by fluorescence microscopy with Hoechst 33258 staining and flow cytometry with Annexin V-FITC/PI double staining. Mitochondrial membrane potential was assessed using JC-1 fluorescence probe and laser confocal scanning microscopy, and intracellular reactive oxygen species levels were measured by $2^{\prime}, 7^{\prime}$-dichlorofluorescein-diacetate staining and flow cytometry. Cytosolic glutathione content was determined using GSH kits. The expression of cytochrome $c$, caspase-3, procaspase-3 and the Bcl-2 family proteins was assessed by western blotting. The results demonstrated that $\beta$-ELE inhibited the proliferation of A549/DDP cells in a time- and dose-dependent manner. Furthermore, $\beta$-ELE enhanced the sensitivity of A549/DDP cells to cisplatin and reversed the drug resistance of A549/DDP cells. Consistent with a role in activating apoptosis, $\beta$-ELE decreased mitochondrial membrane potential, increased intracellular reactive oxygen species concentration and decreased the cytoplasmic glutathione levels in a timeand dose-dependent manner. The combination of $\beta$-ELE and cisplatin enhanced the protein expression of cytochrome $c$,
\end{abstract}

Correspondence to: Professor Yuan-Rong Tu, Department of Thoracic Surgery, The First Affiliated Hospital of Fujian Medical University, Fuzhou, Fujian 355000, P.R. China

E-mail: yao-130@163.com

Key words: lung neoplasms, drug resistance, $\beta$-elemene, reactive oxygen species, mitochondrial membrane potential, apoptosis, A549/DDP cells, glutathione caspase- 3 and Bad, and reduced protein levels of Bcl-2 and procaspase-3 in the A549/DDP lung cancer cells. These results define a pathway of procaspase-3- $\beta$-ELE function that involves decreased mitochondrial membrane potential, leading to apoptosis triggered by the release of cytochrome $c$ into the cytoplasm and the modulation of apoptosis-related genes. The reversal of drug resistance of the A549/DDP cell line by $\beta$-ELE may be derived from its effect in inducing apoptosis.

\section{Introduction}

Lung cancer is generally diagnosed too late to be operable, and consequently, chemotherapy provides the main treatment option for most lung cancer patients (1-3). Furthermore, drug resistance of lung cancer to chemotherapeutic drugs is one of the important causes of the failure of chemotherapy $(4,5)$. $\beta$-elemene $(\beta$-ELE) is a new anticancer drug extracted from Curcuma zedoaria Roscoe, know as zedoary, that includes $\alpha, \beta, \gamma$ and $\delta$ forms. $\beta$-ELE accounts for the main antitumor effect $(6,7)$. $\beta$-ELE injection has been widely used to treat a variety of malignancies including lung cancer (8), liver cancer (9), malignant tumors of the digestive tract (10) and bladder cancer (11). Recently studies have shown that $\beta$-ELE reverses the drug resistance of tumor cells $(7,12,13)$. To explore the mechanisms of action of $\beta$-ELE, we examined the effects of $\beta$-ELE on the cisplatin (DDP)-resistant human lung adenocarcinoma cell line A549/DDP. Our results define a pathway of $\beta$-ELE function involving the regulation of mitochondrial membrane potential and apoptosis signaling proteins leading to the reversal of drug resistance.

\section{Materials and methods}

Reagents and equipment. The cisplatin-sensitive human lung adenocarcinoma cell line, A549, and its cisplatin-resistant derivative, A549/DDP, were purchased from the China Military Medical Science Academy of the PLA (Beijing, China). Cisplatin (DDP) (Yunnan Biological Pharmaceutical Co., Ltd.; batch number: 090202); $\beta$-elemene injection (Dalian Jingang Pharmaceutical Co., Ltd., batch number: 081152); 
mouse monoclonal anti-human antibodies against cytochrome $c$, caspase-3, Bcl-2, Bad and $\beta$-actin; and horseradish peroxidase-labeled rabbit anti-mouse $\operatorname{IgG}$ were obtained from Santa Cruz Biotechnology (Santa Cruz, CA, USA). 2',7'-Dichlorofluorescein diacetate (DCFH-DA) fluorescence probe was purchased from Invitrogen (Carlsbad, CA, USA). Propidium iodide (PI), ECL chemiluminescence reagent kits, Hoechst 33342 staining reagent, MTT cell proliferation assay kits, dimethyl sulfoxide (DMSO), RPMI-1640 culture medium, cyclosporine A and Ac-DEVD-CHO were from Sigma (St. Louis, MO, USA). The Annexin V-FLUOS staining kit was purchased from Roche Diagnostics (Indianapolis, IN, USA). JC-1 mitochondrial membrane potential kits were purchased from Nanjing KeyGen Development Co., Ltd. (Nanjing, China). The GSH/GSSG detection kits were purchased from Jiangsu Pik Wan Biotechnology Research Institute (Jiangsu, China). Equipment used included FACSCalibur flow cytometer (Becton-Dickinson), Tcs SP2 laser scanning confocal microscope (Leica), spectrophotometer (Eppendorf), electrophoresis and transfer film equipment (Bio-Rad), Olympus IX71 fluorescence microscope (Olympus), AE31/CCIS inverted microscope (Moltic Co., Ltd.) and 5804R low speed centrifuge (Eppendorf). $\beta$-ELE and DDP were diluted with both RPMI-1640 and 10\% fetal bovine serum (FBS) medium to various working concentrations when used.

Cell culture. Human lung adenocarcinoma A549 and A549/ DDP cells (final concentration of $2 \mu \mathrm{g} / \mathrm{ml}$ DDP to maintain drug resistance) were cultured in RPMI-1640 medium supplemented with $10 \% \mathrm{FBS}, 100 \mathrm{U} / \mathrm{ml}$ penicillin and $100 \mathrm{mg} / \mathrm{l}$ streptomycin in an atmosphere of $5 \% \mathrm{CO}_{2}$ at $37^{\circ} \mathrm{C}$. The $\mathrm{A} 549 /$ DDP cells were cultured for one week in the medium without DDP prior to experimentation. Exponentially growing cells were used in all experiments.

Drug sensitivity assay. The sensitivity of cells to drugs was determined using the MTT assay. Briefly, cells were plated in triplicate in 96-well plates at a density of $5 \times 10^{3}$ cells/well for the drug sensitivity assays. Cells were treated with $0.25,0.5,1$, 2, 4, 8, 16 or $32 \mu \mathrm{g} / \mathrm{ml}$ of DDP for $24 \mathrm{~h}, 20 \mu \mathrm{l} \mathrm{MTT} \mathrm{dye} \mathrm{(5} \mathrm{mg/}$ $\mathrm{ml}$ ) was added at $37^{\circ} \mathrm{C}$ for $4 \mathrm{~h}$, and then the culture medium was removed and $150 \mu \mathrm{l}$ of DMSO per well was added with oscillation for $10 \mathrm{~min}$. Spectrometric absorbance at $570 \mathrm{~nm}$ was measured by using a microplate reader (reference wavelength $630 \mathrm{~nm}$ ). The experiment was repeated 3 times to generate a growth curve. The proliferation rate $(\%)$ was determined by calculating the value of the experimental group/the value of the control group x $100 \%$.

MTT cytotoxicity assay. A549/DDP cells were plated in triplicate in 96 -well plates at a density of $5 \times 10^{3}$ cells/well. After cells adhered to the plates, a final concentration of 10, 20, 40 or $80 \mu \mathrm{g} / \mathrm{ml} \beta$-ELE was added to the experimental groups, and the same amount of drug dissolution medium was added to the control group. MTT assay was used to determine $\beta$-ELE cytotoxicity as previously described. The cell proliferation inhibition rate was calculated as 1 - the proliferation rate (\%). The $50 \%$ inhibitory concentration $\left(\mathrm{IC}_{50}\right)$ was calculated by linear regression, and the fold of drug resistance was calculated as $\mathrm{IC}_{50}$ of resistant cells/ $\mathrm{IC}_{50}$ of sensitive cells.
For assessing the $\beta$-ELE-mediated reversal of A549/ DDP cell drug resistance, the control group was treated with varying final concentrations of DDP $(0.25-32 \mu \mathrm{g} / \mathrm{ml})$, and the experimental group was additionally treated with $20 \mu \mathrm{g} / \mathrm{ml}$ $\beta$-ELE. After $24 \mathrm{~h}$, MTT solution was added, and the absorbance was measured as described above. The fold of reversal was calculated as the $\mathrm{IC}_{50}$ value in the absence of $\beta$-ELE to that in the presence of $\beta$-ELE.

Apoptosis assay. A549/DDP cells were cultured in $2 \mu \mathrm{g} /$ $\mathrm{ml}$ DDP to maintain drug resistance, and $\beta$-ELE was added at 20 or $40 \mu \mathrm{g} / \mathrm{ml}$ to the experimental group. After $24 \mathrm{~h}$, the cells were collected by centrifugation for Hoechst and Annexin V-FITC staining. For Hoechst staining, nuclei were stained with DNA fluorescent dye and observed under a fluorescence microscope. For Annexin V-FITC staining, the cell pellet was re-suspended in $100 \mu \mathrm{l}$ binding buffer containing $10 \mathrm{mM}$ HEPES/NaOH, $140 \mathrm{mM} \mathrm{NaCl}, 5 \mathrm{mM} \mathrm{CaCl}{ }_{2}$ (pH 7.4), supplemented with $5 \mu \mathrm{l}$ Annexin V-FITC and $5 \mu \mathrm{l}$ PI. After the incubation period ( $30 \mathrm{~min}$ at $37^{\circ} \mathrm{C}$ in the dark), an additional $400 \mu \mathrm{l}$ of binding buffer was added and Annexin V-FITC/ PI staining was analyzed within $1 \mathrm{~h}$ by flow cytometry. The fluorescence intensity (green FL1-H and red FL2-H) was measured on the FACSCalibur flow cytometer. CellQuest Pro software was used for acquisition and analysis of data.

Assessment of mitochondrial membrane potential ( $\Delta \Psi \mathrm{\Psi})$ by JC-1 assay and laser confocal fluorescence microscopy. A549/DDP cells were plated in triplicate in 96-well plates at a density of $1 \times 10^{5}$ cells/well. The control group was plated in $2 \mu \mathrm{g} / \mathrm{ml}$ DDP, and an additional $40 \mu \mathrm{g} / \mathrm{ml} \beta$-ELE was added to the experimental group. Cells were cultured for $0,6,12$ or $24 \mathrm{~h}$ in serum-free culture medium, and then $10 \mathrm{mg} / \mathrm{l} \mathrm{JC}-1$ dye was added and cells were incubated at $37^{\circ} \mathrm{C}$ for $15 \mathrm{~min}$. Cells were centrifuged, and the excess waste dye was aspirated. Cells were then photographed under a laser confocal microscope, and JC-1 monomer (green fluorescence) was detected at an excitation wavelength of $488 \mathrm{~nm}$ (emission wavelength $530 \mathrm{~nm}$ ), while JC-1 polymer (red fluorescence) was detected at an excitation wavelength of $535 \mathrm{~nm}$ (emission wavelength $590 \mathrm{~nm}$ ). Ten fields were randomly selected for calculation of the average fluorescence intensity (Leica, LCS Universal Imaging software). The red fluorescence/green fluorescence optical density ratio indicated the mitochondrial $\Delta \Psi \mathrm{m}$ levels, while a decrease in the optical density ratio represented mitochondrial $\Delta \Psi \mathrm{m}$ decrease.

Assessment of intracellular reactive oxygen species (ROS) and the level of glutathione (GSH). In order to assess intracellular ROS levels, A549/DDP cells were plated in triplicate in 96 -well plates at a density of $5 \times 10^{3}$ cells/well with $2 \mu \mathrm{g} / \mathrm{ml} \mathrm{DDP}$ and 0,20 or $40 \mu \mathrm{g} / \mathrm{ml} \beta$-ELE for $24 \mathrm{~h}$. Cells were collected, incubated with $5 \mu \mathrm{M}$ DCF-DA probe at $37^{\circ} \mathrm{C}$ for $20 \mathrm{~min}$ in serum-free medium, and washed 3 times, and the fluorescence intensity at a 488 -nm excitation wavelength and 525-nm emission wavelength was detected by flow cytometry. DCFH-DA itself has no fluorescence and can freely pass through the cell membrane. After entering the cell, 2',7'-dichlorofluorescein (DCFH) is oxidized by the superoxide anion and hydrogen peroxide to fluorescent 


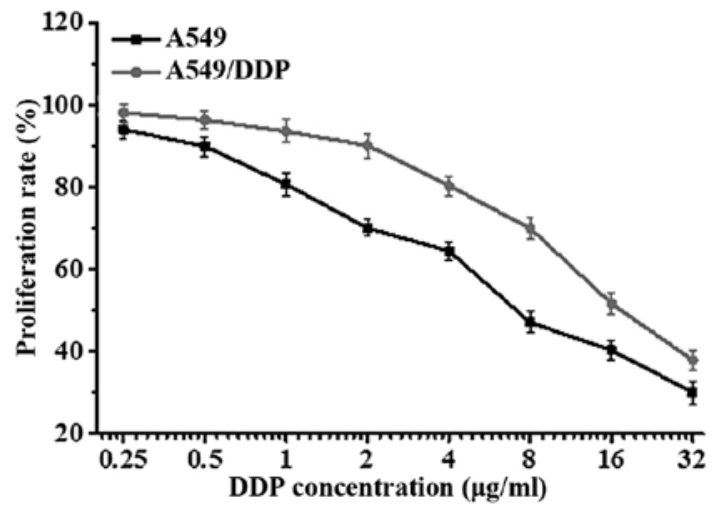

Figure 1. Growth inhibitory effects of different concentrations of DDP on A549 and A549/DDP cells. Cell viability, as assessed by MTT assay, was determined $24 \mathrm{~h}$ after exposure of A549 or A549/DDP cells to increasing concentrations of cisplatin (DDP). Results represent the average of triplicate wells and are representative of three independent experiments.

2',7'-dichlorofluorescein (DCF). The level of DCF reflects the level of intracellular ROS expression.

At the same time, we measured GSH according to the manufacturer's instructions. We measured total glutathione $(\mathrm{GSSG}+\mathrm{GSH})$ content, and then subtracted the amount of GSH in the sample to calculate the GSSG content. The ratio of $\mathrm{GSH} /(\mathrm{GSSG}+\mathrm{GSH})$ was used as a measure of $\mathrm{GSH}$. The principle of this assay is as follows: GSH reacts with 5 '-dinitrobenzene acid (DTNB) to form GSSG and stable 5-mercapto-2-nitrobenzene acid (TNB); GSSG is reduced by GSSG reductase and NADPH, releasing additional TNB (yellow color), which can be detected by spectrophotometry (maximum absorbance wavelength $412 \mathrm{~nm}$ ). The amount of TNB is proportional to the GSH released in the samples. All experiments were repeated 3 times.

Western blot analysis of cytochrome c, caspase-3 and Bcl-2 expression. A549/DDP cells were plated in triplicate in 96-well plates at a density of $5 \times 10^{3}$ cells/well with $2 \mu \mathrm{g} / \mathrm{ml}$ DDP plus 0,20 or $40 \mu \mathrm{g} / \mathrm{ml} \beta$-ELE. Cells were then collected in lysis buffer and incubated on ice for $15 \mathrm{~min}$. The lysates were centrifuged at $4^{\circ} \mathrm{C}$ for $10 \mathrm{~min}$, and $50 \mu \mathrm{g}$ of protein was eletrophoresed by $12 \%$ SDS-PAGE and transferred to polyvinyl difluoride ethylene membranes. The membranes were then blocked with 5\% skim milk for $2 \mathrm{~h}$, washed in TBST, and incubated with mouse anti-human cytochrome $c$ (1:800 dilution), caspase-3 (1:1,000 dilution), Bcl-2 (1:1,000 dilution), Bad (1:1,000 dilution), procaspase-3 (1:1,000 dilution) or $\beta$-actin (1:2,000 dilution). HRP-labeled secondary antibodies (1:2,000 dilution) were added for $2 \mathrm{~h}$ at room temperature, followed by ECL chemiluminescence. For assessment of the effects of cyclosporine and Ac-DEVD-CHO, cells were divided into 4 groups (each with $2 \mu \mathrm{g} / \mathrm{ml}$ DDP to maintain drug resistance): control group; $40 \mu \mathrm{g} / \mathrm{ml} \beta$-ELE treatment group; $40 \mu \mathrm{g} / \mathrm{ml}$ $\beta$-ELE + Ac-DEVD-CHO (50 $\mu \mathrm{mol} / \mathrm{l})$ treatment group; and $40 \mu \mathrm{g} / \mathrm{ml} \beta$-ELE + cyclosporine A $(2 \mu \mathrm{mol} / \mathrm{l})$ treatment group. Caspase- 3 expression and cleavage were assessed by western blot analysis as described above.

Statistical analysis. Statistical analysis was performed using SPSS 13.5 and Origin 8.5 software. Statistical data represent

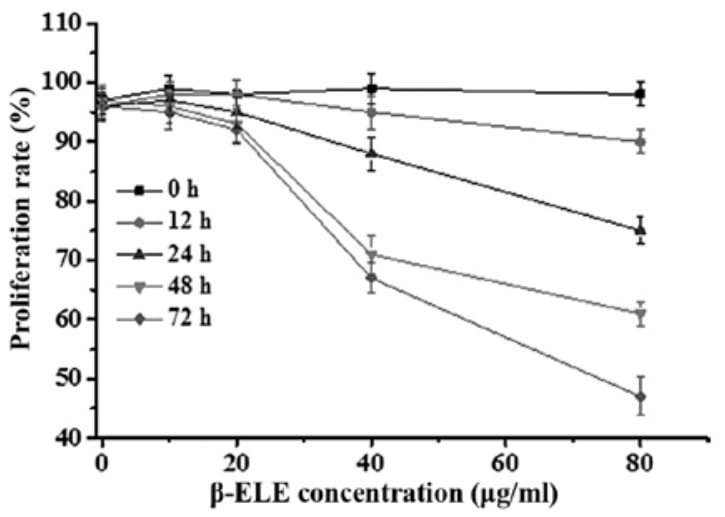

Figure 2. Time- and dose-dependent growth inhibitory effects of $\beta$-ELE on A549/DDP cells. Cell viability, as assessed by MTT assay, was determined at a range of times after A549/DDP cells were exposed to increasing concentrations of cisplatin (DDP). Viability was normalized to $100 \%$ at time zero. Results represent the average of triplicate wells and are representative of three independent experiments.

mean \pm SD and were determined using single factor analysis of variance. Comparisons between two groups were performed using a Student's t-test or $\chi^{2}$ test. $\mathrm{P}<0.05$ was considered to indicate a statistically significant result.

\section{Results}

Determination of A549 and A549/DDP cell drug sensitivity. To verify the differential sensitivity of A549 and its derivative cell line, A549/DDP, to DDP (cisplatin), cells were exposed to a gradient of DDP concentrations for $24 \mathrm{~h}$, and cell viability was assessed by MTT assay. Results showed that the concentration of DDP required to inhibit the proliferation of A549 cells $\left(\mathrm{IC}_{50}=5.73 \pm 2.11 \mu \mathrm{g} / \mathrm{ml}\right)$ was lower than the concentration needed to inhibit the proliferation of A549/DDP cells $\left(\mathrm{IC}_{50}=15.34 \pm 1.05 \mu \mathrm{g} / \mathrm{ml}\right.$ ) (Fig. 1). The difference in $\mathrm{IC}_{50}$ was statistically significant $(\mathrm{t}=2.3571, \mathrm{P}<0.01)$, confirming that the A549/DDP cells were DDP-resistant.

Effects of $\beta$-ELE on A549/DDP cell toxicity. To assess the effects of $\beta$-ELE on A549/DDP cells, we performed MTT assays over a range of doses and times. Results showed that $\beta$-ELE inhibited A549/DDP cell growth in dose-dependent manner (Fig. $2 ; 20$ vs. $40 \mu \mathrm{g} / \mathrm{ml} \beta$-ELE: $\chi^{2}=2.6249, \mathrm{P}<0.05$ at $24 \mathrm{~h} ; \chi^{2}=2.1449, \mathrm{P}<0.05$ at $48 \mathrm{~h}$ ). This effect was also partially time-dependent, depending on $\beta$-ELE dose ( 24 vs. $48 \mathrm{~h}$ for $20 \mu \mathrm{g} / \mathrm{ml} \beta$-ELE: $\chi^{2}=27.4632, \mathrm{P}>0.05$; for $40 \mu \mathrm{g} / \mathrm{ml} \beta$-ELE: $\left.\chi^{2}=2.4136, \mathrm{P}<0.05\right)$. Based on these results, we selected $20 \mu \mathrm{g} / \mathrm{ml}$ ELE treatment for $24 \mathrm{~h}$ as the optimum concentration and time that ELE reverses the drug resistance of A549/ DDP cells.

$\beta$-ELE reverses drug resistance of A549/DDP cells. To determine whether $\beta$-ELE can reverse the drug resistance of A549/DDP cells, we exposed cells for $24 \mathrm{~h}$ to a range of doses of DDP in the absence or presence of $20 \mu \mathrm{g} / \mathrm{ml} \beta$-ELE. The $\beta$-ELE-treated cells showed increased sensitivity to DDP at all concentrations (Fig. 3; $\mathrm{P}<0.05$ ). Furthermore, the $\mathrm{IC}_{50}$ value of the experimental group $(4.15 \pm 0.89 \mu \mathrm{g} / \mathrm{ml})$ was significantly lower than the $\mathrm{IC}_{50}$ value of the control group 


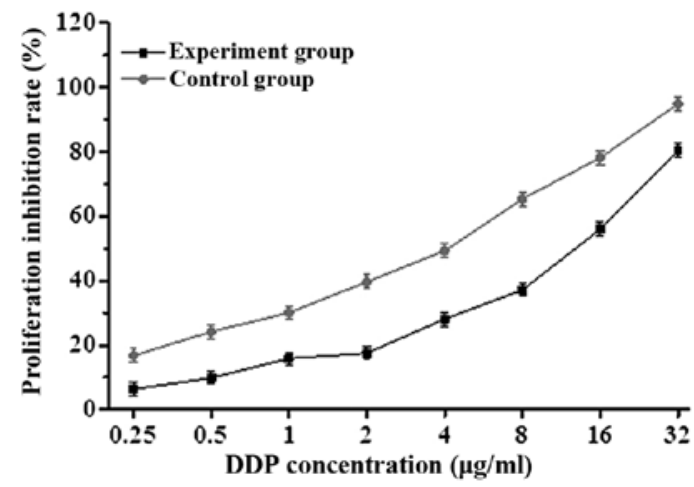

Figure 3. Effect of $\beta$-ELE on DDP-mediated inhibition of A549/DDP cell proliferation. Proliferation inhibition rate (the percentage in decrease of the initial number of cells) was determined by MTT assays $24 \mathrm{~h}$ after exposure to either a range of concentrations of DDP (control group) or $20 \mu \mathrm{g} / \mathrm{ml} \beta$-ELE plus a range of concentrations of DDP (experimental group). The values corresponding to this graph and the associated statistical analysis are provided in Table I. Results represent the average of three experiments performed in triplicate.

$(15.46 \pm 1.23 \mu \mathrm{g} / \mathrm{ml})(\mathrm{t}=1.4321, \mathrm{P}<0.01)$, with the drug resistance ratio reversed $3.73 \pm 0.38$-fold (Table I and Fig. 3). The results indicate that $\beta$-ELE enhances the sensitivity of A549/DDP cells to DDP.

$\beta-E L E$ increases levels of A549/DDP cell apoptosis. To determine whether the enhanced sensitivity to DDP conferred by $\beta$-ELE is related to increased levels of apoptosis, we performed Hoechst 33342 fluorescent staining following $\beta$-ELE treatment. Results showed that upon treatment with 20 and $40 \mu \mathrm{g} / \mathrm{ml} \beta$-ELE for $24 \mathrm{~h}$, A549/DDP cell nuclei became progressively smaller with more dense granular chromatin staining, which suggests typical morphological changes of apoptosis (Fig. 4A). We verified these findings by flow cytometry following Annexin V-FITC/PI staining. Our results demonstrated a dose-dependent increase in the apoptosis rate for cells treated with 20 and $40 \mu \mathrm{g} / \mathrm{ml} \beta$-ELE as compared to the control, which was apparent for cells in early apoptosis (17.61 \pm 0.10 and $37.80 \pm 0.12 \%$ vs. $5.73 \pm 0.09 \%$, respectively) and cells in middle-late apoptosis $(18.9 \pm 0.11$ and $32.4 \pm 0.13$ vs. $17.3 \pm 0.11 \%$, respectively). The differences between these values were statistically significant $(\mathrm{P}<0.05)$ (Fig 4B). Collectively, these results suggest that $\beta$-ELE increases the levels of apoptosis in A549/DDP cells.

$\beta$-ELE decreases the mitochondrial membrane potential of A549/DDP cells. During apoptosis, the mitochondrial membrane potential decreases $(14,15)$. As an additional verification of the effects of $\beta$-ELE, we assessed the mitochondrial membrane potential of A549/DDP cells before and after a 6-, 12- and 24-h drug treatment. Most of the control cells were stained red by JC-1 assay, indicating an intact cell membrane, with clearly visible nuclei. In contrast, cells treated with 20 or $40 \mu \mathrm{g} / \mathrm{ml} \beta$-ELE showed increasing amounts of green fluorescence, cell rupture and cell content outflow, suggesting a decline in the mitochondrial $\Delta \Psi \mathrm{m}$. The effect was more obvious for the $40 \mu \mathrm{g} / \mathrm{ml} \beta$-ELE group, which showed clear pyknosis (Fig. 5A). Analysis of the red/green fluorescent light density ratio showed that the decrease was time-dependent
Table I. Effect of $\beta$-ELE in reversing the drug resistance of A549/DDP cells ( $n=3$, mean \pm SD).

\begin{tabular}{|c|c|c|}
\hline \multirow[b]{2}{*}{$\operatorname{DDP}(\mu \mathrm{g} / \mathrm{ml})$} & \multicolumn{2}{|c|}{ Cell proliferation inhibition rate $(\%)$} \\
\hline & Control group & Experimental group \\
\hline 0.25 & $6.35 \pm 1.03$ & $16.79 \pm 1.85^{\mathrm{a}}$ \\
\hline 0.5 & $9.88 \pm 0.99$ & $24.20 \pm 0.13^{\mathrm{a}}$ \\
\hline 1 & $15.89 \pm 0.46$ & $30.14 \pm 0.47^{\mathrm{a}}$ \\
\hline 2 & $17.55 \pm 1.35$ & $39.64 \pm 0.09^{\mathrm{a}}$ \\
\hline 4 & $28.11 \pm 0.65$ & $49.34 \pm 0.05^{\mathrm{a}}$ \\
\hline 8 & $37.21 \pm 1.45$ & $65.37 \pm 1.05^{\mathrm{a}}$ \\
\hline 16 & $55.96 \pm 2.03$ & $78.21 \pm 0.79^{\mathrm{a}}$ \\
\hline 32 & $80.44 \pm 0.77$ & $94.85 \pm 0.91^{\mathrm{a}}$ \\
\hline
\end{tabular}

${ }^{\mathrm{a}} \mathrm{P}<0.05$ vs. control group (A549/DDP cells treated with different concentrations of DDP). Experimental group, $\beta$-ELE $(20 \mu \mathrm{g} / \mathrm{ml})$ combined with different concentrations of DDP.

and was statistically significant for the 20 and $40 \mu \mathrm{g} / \mathrm{ml} \mathrm{ELE}$ groups $\left(6 \mathrm{~h}: \chi^{2}=2.2447, \mathrm{P}<0.05, \chi^{2}=2.0256, \mathrm{P}<0.05 ; 12 \mathrm{~h}\right.$ : $\chi^{2}=2.0143, \mathrm{P}<0.05, \chi^{2}=1.3121, \mathrm{P}<0.01 ; 24 \mathrm{~h}: \chi^{2}=1.3084, \mathrm{P}<0.01$, $\chi^{2}=1.0034, \mathrm{P}<0.01$ ) (Fig. 5B).

$\beta$-ELE increases levels of reactive oxygen species (ROS) generation and glutathione (GSH) release in A549/DDP cells. The generation of ROS and decline in intracellular GSH levels are also associated with apotosis $(16,17)$. To examine the ROS levels, we performed a DCF assay following treatment with $\beta$-ELE for $24 \mathrm{~h}$. Results showed a statistical increase in DCF fluorescence intensity $\left(\chi^{2}=3.2443, \mathrm{P}<0.05 ; \chi^{2}=2.1254, \mathrm{P}<0.05\right.$, respectively) in the cells treated with 20 or $40 \mu \mathrm{g} / \mathrm{ml} \beta$-ELE. These results suggest that the content of ROS was increased by $\beta$-ELE treatment (Fig. 6A). Further assessment of GSH levels showed that the GSH/(GSSG + GSH) ratio decreased, suggesting a dose-dependent decrease in GSH content $\left(\chi^{2}=2.8437, \mathrm{P}<0.05 ; \chi^{2}=2.1244, \mathrm{P}<0.05\right)$ (Fig. 6B). These results suggest that $\beta$-ELE activates a pathway of apoptosis that involves both the generation of ROS and decline in intracellular GSH.

$\beta$-ELE activates apoptosis in A549/DDP cells through a pathway involving caspase-3 activation, modulation of Bcl-2 family protein expression and cytochrome c release. Apoptosis may be accompanied by the cleavage of procaspase- 3 to active caspase-3, the modulation of Bcl-2 family protein expression and the release of cytochrome $c$ (18-20). To assess the effects of $\beta$-ELE on these signaling pathways, we performed western blotting of A549/DDP cells following a 24-h treatment. Compared with the control group, cells treated with 20 and $40 \mu \mathrm{g} / \mathrm{ml} \beta$-ELE had 0.75 - and 0.48 -fold less procaspase-3 $\left(\chi^{2}=3.8782, \mathrm{P}<0.05 ; \chi^{2}=3.9644, \mathrm{P}<0.05\right.$, respectively), while a 1.39- and 1.72-fold increase was noted in cleaved caspase-3 $\left(\chi^{2}=2.1134, \mathrm{P}<0.05 ; \chi^{2}=2.3516, \mathrm{P}<0.05\right.$, respectively) (Fig. 7). This indicates a shift from inactive to active caspase-3. Cells treated with 20 and $40 \mu \mathrm{g} / \mathrm{ml} \beta$-ELE also had 0.55-0.33-fold less of the anti-apoptotic Bcl-2 $\left(\chi^{2}=3.9442, \mathrm{P}<0.05 ; \chi^{2}=4.0142\right.$, 
$\mathbf{A}$

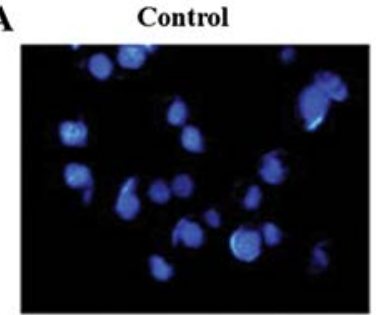

B

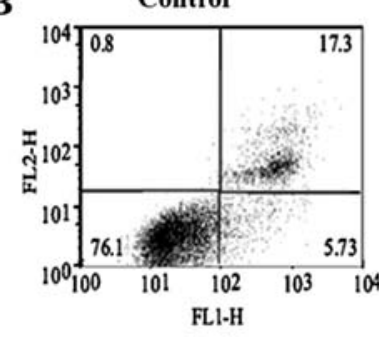

B-ELE $20 \mu \mathrm{g} / \mathrm{ml}$

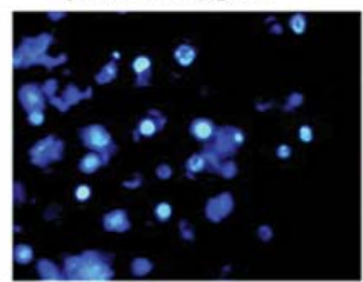

B-ELE $20 \mu \mathrm{g} / \mathrm{ml}$

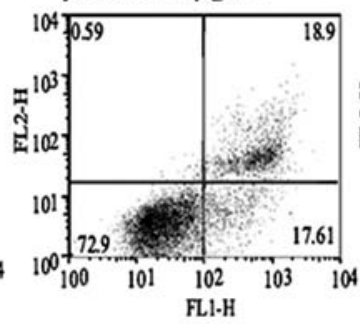

B-ELE $40 \mu \mathrm{g} / \mathrm{ml}$

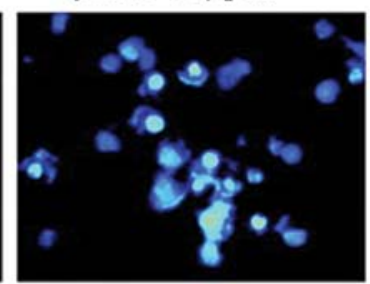

B-ELE $40 \mu \mathrm{g} / \mathrm{ml}$

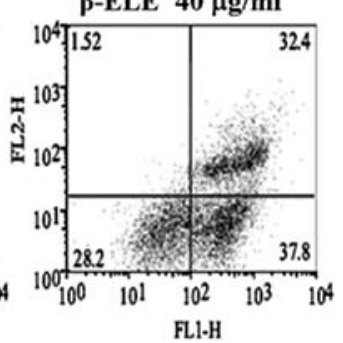

Figure 4. $\beta$-ELE induces cellular morphological features of apoptosis. (A) A549/DDP cells were exposed to 0,20 and $40 \mu \mathrm{g} / \mathrm{ml} \beta$-ELE for $24 \mathrm{~h}$, and then were stained with Hoechst. The small nuclei and condensed granular blue chromatin staining noted in the $\beta$-ELE-treated cells represent typical apoptotic morphology (fluorescence staining, x400). (B) The levels of apoptosis in A549/DDP cells exposed to 0, 20 and $40 \mu \mathrm{g} / \mathrm{ml} \beta$-ELE were determined by Annexin V-FITC/PI staining. Cells positive for Annexin V-FITC alone represent early apoptotic cells, while cells positive for staining with both chromagens represent middle to late apoptotic cells. Results are representative of three experiments.

A
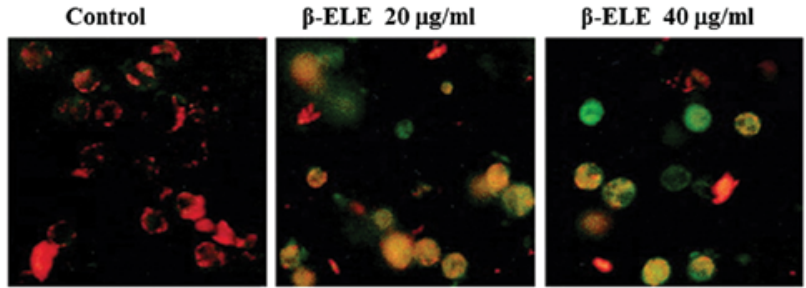

B

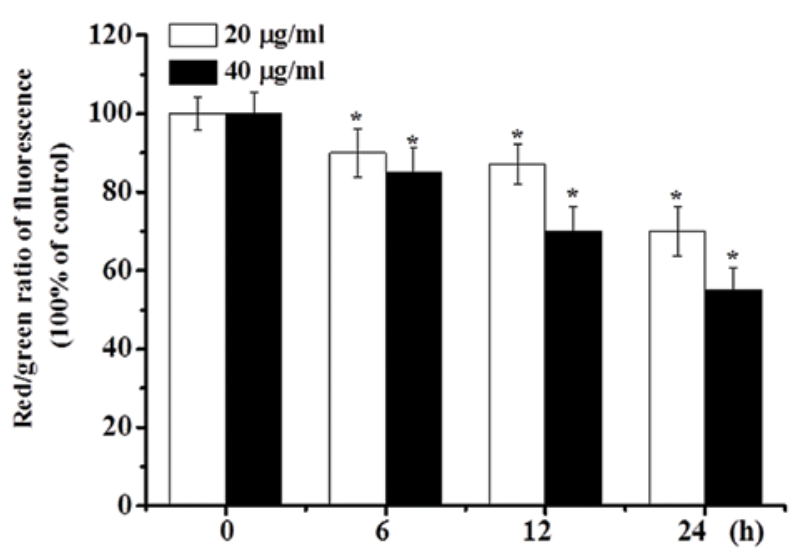

Figure 5. $\beta$-ELE induces an increase in the mitochondrial membrane potential of A549/DDP cells. (A) Mitochondrial membrane potential was measured by laser confocal scanning microscopy for cells exposed to 0,20 or $40 \mu \mathrm{g} / \mathrm{ml}$ $\beta$-ELE (x400). Red represents resting cells, while green represents cells with decreased membrane potential. (B) The ratio of red/green was compared at different times of exposure to $\beta$-ELE. Values are standardized to $100 \%$ in the untreated cells and represent the average \pm SD of triplicate wells. Results are representative of three independent experiments. ${ }^{*} \mathrm{P}<0.05$ vs. control group.

$\mathrm{P}<0.05)$ and 1.51-1.82-fold more of the pro-apoptotic Bad protein $\left(\chi^{2}=1.9641, \mathrm{P}<0.05 ; \chi^{2}=1.8746, \mathrm{P}<0.05\right)$. In addition, a 1.43- and 1.63 -fold increase in cytoplasmic cytochrome $c$ levels $\left(\chi^{2}=1.9642, \mathrm{P}<0.05 ; \chi^{2}=1.7692, \mathrm{P}<0.05\right)$ was also consistent with increased apoptosis. These results suggest that $\beta$-ELE
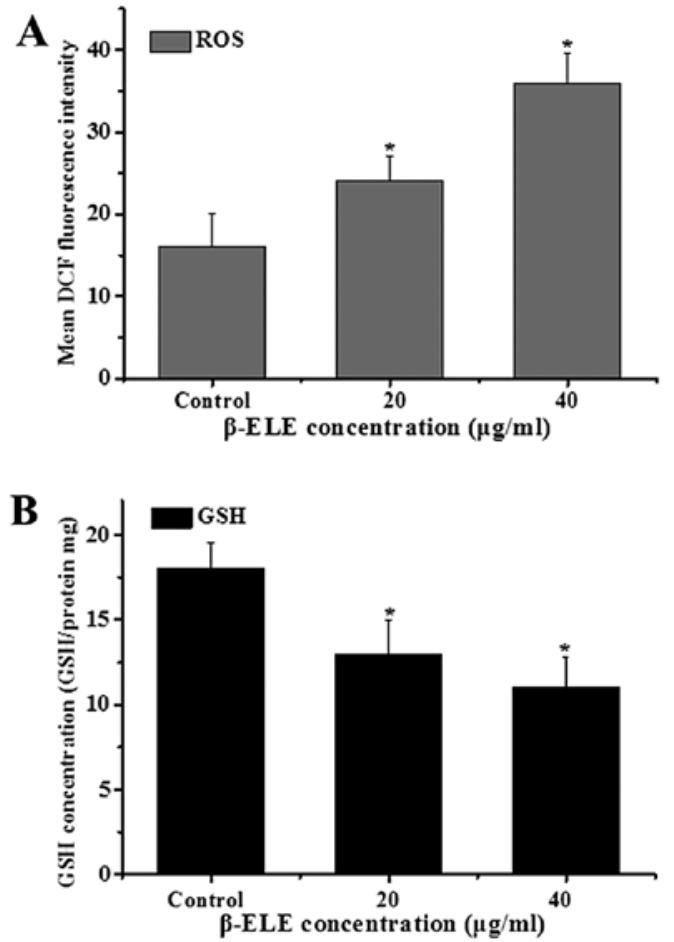

Figure 6. $\beta$-ELE promotes an increase in the ROS concentration and decrease in the GSH level in A549/DDP cells. (A) The mean DCF fluorescence intensity is shown as a measure of ROS activity $24 \mathrm{~h}$ after exposure of A549/DDP cells to 0,20 or $40 \mu \mathrm{g} / \mathrm{ml} \beta$-ELE. (B) GSH levels are shown $24 \mathrm{~h}$ after exposure of A549/DDP cells to 0,20 or $40 \mu \mathrm{g} / \mathrm{ml} \beta$-ELE. Values represent the average \pm SD of triplicate wells and are representative of three independent experiments. ${ }^{*} \mathrm{P}<0.05$ vs. control group.

damages the mitochondrial membrane, leading to the release of mitochondrial cytochrome $c$ to the cytoplasm, which also leads to the activation of caspase- 3 and modulation of Bcl-2 

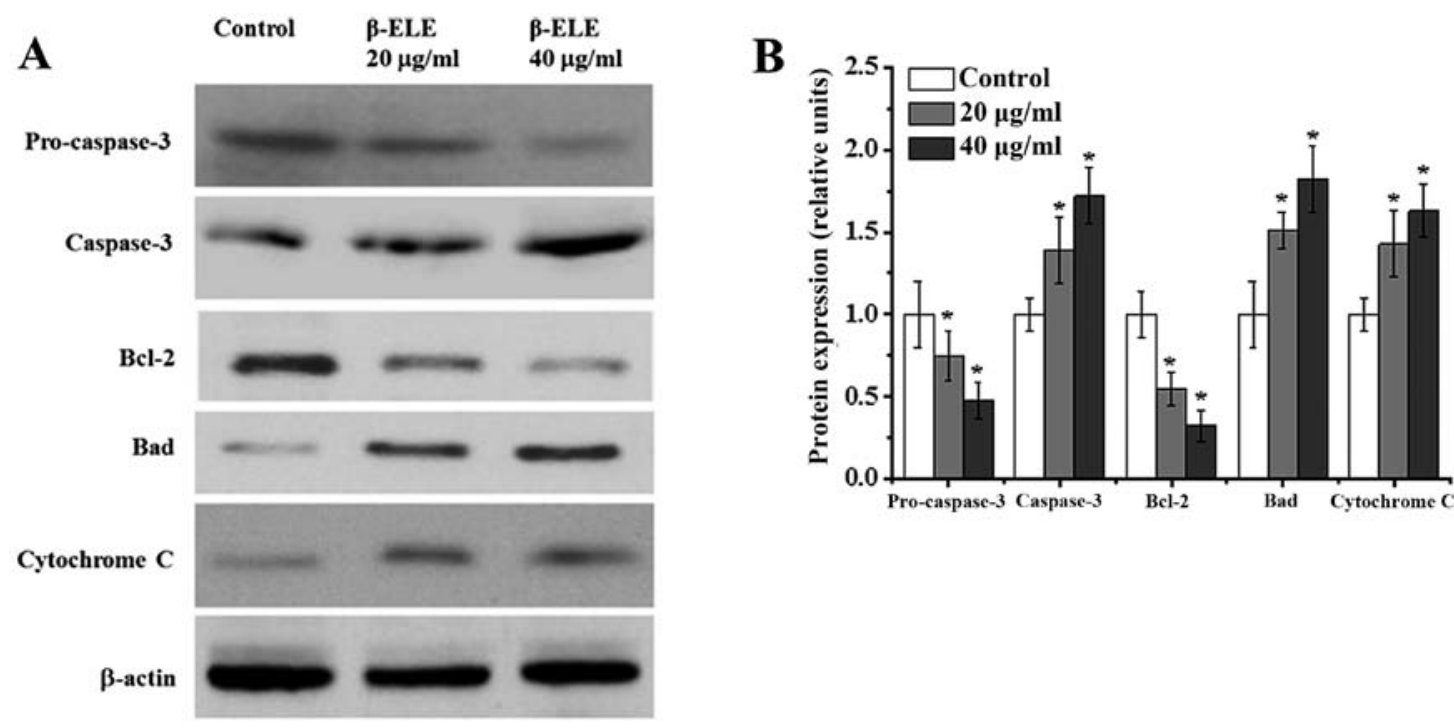

Figure 7. The levels of cytoplasmic cytochrome $c$, caspase and Bcl-2 family proteins in A549/DDP cells are modulated by $\beta$-ELE. (A) Representative western blots are shown for A549/DDP cells exposed to 0,20 or $40 \mu \mathrm{g} / \mathrm{ml} \beta$-ELE for $24 \mathrm{~h}$. $\beta$-actin is shown as a loading control. (B) The mean \pm SD of the intensity (grey value) of the western blot bands from 3 independent experiments for the treatment groups in panel A. Results are standardized to 1 as assigned to the untreated control cells. ${ }^{\mathrm{P}}<0.05$ vs. control group.

A

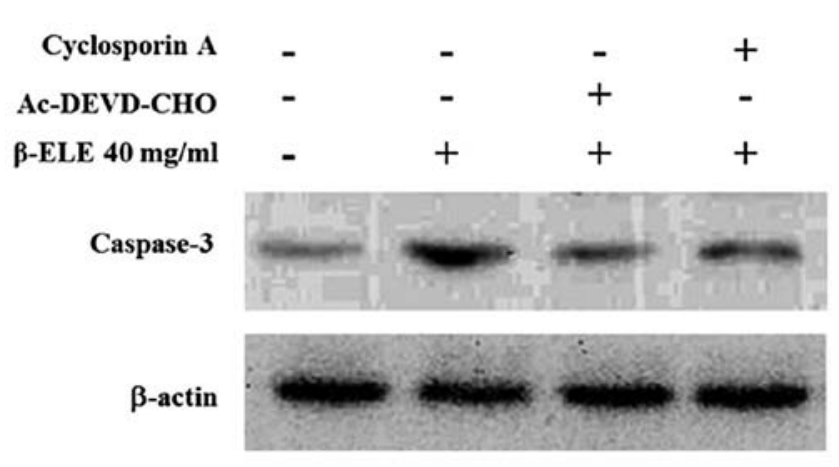

B

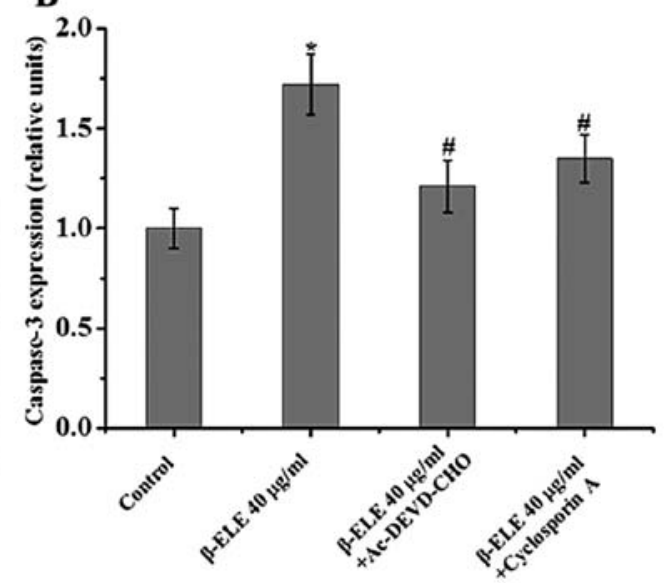

Figure 8. Cyclosporine A and Ac-DEVD-CHO inhibit caspase-3 protein expression in $\beta$-ELE-treated A549/DDP cells. (A) Representative western blots are shown for A549/DDP cells exposed for $24 \mathrm{~h}$ to $40 \mu \mathrm{g} / \mathrm{ml} \beta$-ELE alone or in combination with cyclosporine A or Ac-DEVD-CHO. $\beta$-actin is shown as a loading control. (B) The mean \pm SD intensity (grey value) of the western blot bands were determined from 3 independent experiments for the treatments in panel A. Results are standardized to 1 as assigned to the untreated control cells. ${ }^{*} \mathrm{P}<0.05$ vs. control group, ${ }^{*} \mathrm{P}<0.05 \mathrm{vs} .40 \mu \mathrm{g} / \mathrm{ml} \beta$-ELE group.

family proteins to activate an apoptotic pathway that reverses drug resistance.

Cyclosporine A and Ac-DEVD-CHO inhibit $\beta$-ELE-induced apoptosis in A549/DDP cells. To further understand the role of the mitochondrial membrane and apoptotic pathways in the reversal of multidrug resistance, we treated A549/DDP cells with $40 \mu \mathrm{g} / \mathrm{ml} \beta$-ELE for $24 \mathrm{~h}$ in combination with the mitochondrial membrane permeability transition pore blocking agent cyclosporine $\mathrm{A}$ and the caspase-3 inhibitor Ac-DEVD-CHO. Results showed that the addition of either cyclosporine A or Ac-DEVD-CHO activated a $1.72 \pm 0.13 \%$ increase in the $\beta$-ELE-treated group compared with the control group; $0.68 \pm 0.14$-fold for $\beta$-ELE cells + cyclosporine $A$ vs. $\beta$-ELE group; $1.35 \pm 0.15$-fold for $\beta$-ELE cells +
Ac-DEVD-CHO vs. $\beta$-ELE group. The decrease in $\beta$-ELE activation by cyclosporine A and Ac-DEVD-CHO was statistically significant $(\mathrm{P}<0.05)$ (Fig. 8). These results indicate that the mitochondrial membrane integrity and caspase-3 activation play an important role in $\beta$-ELE-induced A549/DDP cell apoptosis.

\section{Discussion}

Apoptosis is a form of programmed cell death that occurs naturally to maintain homeostasis, but can be circumvented by cancer cells (21). Researchers originally thought that apoptosis occurs primarily in response to nuclear changes (22); however, it is now acknowledged that the mitochondrion is the apoptosis control center $(23,24)$. We used the JC-1 fluorescent 
probe detection method to assess changes in the mitochondrial membrane potential following $\beta$-ELE treatment.

Our results indicated that $\beta$-ELE caused pyknosis, cell rupture and outflow of contents. Further analysis revealed that the effects were time- and dose-dependent and were accompanied by a decrease in the mitochondrial membrane potential. Decline in the membrane $\Delta \Psi \mathrm{m}$ is a hallmark of apoptosis initiation and is indicative of membrane damage. Therefore, these results indicate that $\beta$-ELE reverses drug resistance in A549/DDP cells by inducing damage to the mitochondrial membrane and decreasing membrane potential.

Mitochondria are the 'energy processing plants' of biology. Failure or inhibition of the respiratory electron transport chain leads to increased mitochondrial ROS, an activated oxygen free radical that attacks the mitochondrial membrane and decreases mitochondrial $\Delta \Psi \mathrm{m}$, resulting in increased permeability (25). We demonstrated that the decreased mitochondrial membrane potential in A549/DDP cells was accompanied by increased ROS, suggesting a pathway of apoptosis induced by $\beta$-ELE. We also observed a decrease in intracellular GST levels. GST is the scavenger of oxygen free radicals that removes intracellular ROS that accumulates during cellular injury (26). Therefore, our results indicate that $\beta$-ELE reverses A549/DDP cell drug resistance through increased ROS contents in cells which leads to a reduced intracellular GSH content. These intracellular mediators, in turn, cause further aggravation of the damage to the mitochondrial membrane, resulting in further progression towards apoptosis. This cycle is consistent with the results of Yang et al (27) who demonstrated that application of fucoidan to the hepatocellular carcinoma cell line SMMC-7721 activated an increase in ROS, a decreased in GSH, mitochondrial membrane depolarization, and the induction of apoptosis.

A decline in mitochondrial membrane potential $(\Delta \Psi \mathrm{m})$ and increase in permeability is also associated with cytochrome $c$. Cytochrome $c$ is released and activation of caspase cascade ensues. Caspase-3 is irreversibly activated through cleavage of procaspase-3, resulting in the activation of an apoptotic program. Cytochrome $c$ released to the cytoplasmic is mediated by Bcl-2 family proteins on the outer mitochondrial membrane. The Bcl-2 family of proteins includes both anti-apoptotic (Bcl-2, Bcl-xL) and pro-apoptotic (Bax, Bad) proteins. Cytochrome $c$ is located in the mitochondrial intermembrane space, so it cannot normally be detected in the cytoplasm. When the structure of the mitochondrial membrane is damaged, particularly the mitochondrial permeability transition pore (PTP) between the outer and inner membranes, mitochondrial membrane permeability increases, cytochrome $c$ is released into the cytoplasm across the membrane, which leads to depolarization, change in mitochondrial membrane permeability and caspase- 3 activation; thus, cytochrome $c$ is one of the key factors in apoptosis signal transduction. However, the release of cytochrome $c$ is modulated by effects of the Bcl-2 family proteins on PTP on the mitochondrial membrane. A decrease in anti-apoptotic Bcl-2 family proteins (such as Bcl-2, Bcl-xL) and an increase in pro-apoptotic proteins (e.g., Bax, Bad) further promote the release of cytochrome $c$ into the cytoplasm, triggering the caspase cascade and inducing increased apoptosis (28-35). We demonstrated that $\beta$-ELE promotes a dose-dependent increase in cytoplasmic cytochrome $c$, transition of caspase-3 to its active form, a decrease in the expression of anti-apoptotic Bcl-2, and an increase in pro-apoptotic Bad. Therefore, our results suggest a pathway of apoptosis activated by $\beta$-ELE that involves characteristic mitochondrial changes. Further study demonstrated that caspase- 3 expression was reduced by the addition of either the mitochondrial PTP inhibitor cyclosporine A or caspase-3 inhibitor Ac-DEVD-CHO. These results verify the relationship between mitochondrial permeability and caspase- 3 activation in this pathway. In summary, our results demonstrated that $\beta$-ELE reverses A549/DDP cell drug resistance via cytochrome $c$ release, caspase activation and modulation of the expression of Bcl-2 family proteins. These results provide a mechanism for $\beta$-ELE that may explain its ability to overcome drug resistance and could be useful in the treatment of drug-resistance cancers.

\section{Acknowledgements}

The present study was supported by the Fujian Provincial Natural Science Foundation, China (no. 2010D014).

\section{References}

1. Cicenas S, Zaliene A and Atkocius V: Treatment outcome of locally advanced stage IIIA/B lung cancer. Medicina (Kaunas) 45: 452-459, 2009 (In Lithuanian).

2. Szkorupa M, Klein J, Bohanes T, et al: Neoadjuvant chemotherapy and surgical treatment in advanced stages of non-small cell lung cancer. Rozhl Chir 90: 433-439, 2011 (In Czech).

3. Spásová I: The position of neoadjuvant chemotherapy in the treatment of non-small-cell lung carcinoma. Vnitr Lek 53: 715-723, 2007 (In Czech).

4. Lee Y, Kim HY, Lee SH, et al: Clinical significance of heterogeneity in response to retreatment with epidermal growth factor receptor tyrosine kinase inhibitors in patients with lung cancer acquiring secondary resistance to the drug. Clin Lung Cancer 15: 145-151, 2014.

5. Goldberg SB, Oxnard GR, Digumarthy S, et al: Chemotherapy with erlotinib or chemotherapy alone in advanced non-small cell lung cancer with acquired resistance to EGFR tyrosine kinase inhibitors. Oncologist 18: 1214-1220, 2013.

6. Ju JF, Yu WP, Fu CS and Ma LM: Modern research and clinical application of $\beta$-elemene. Qilu Pharm Affairs 27: 546-548, 2008.

7. Guo HQ, Zhang GN, Wang YJ, et al: $\beta$-elemene, a compound derived from Rhizoma zedoariae, reverses multidrug resistance mediated by the ABCB1 transporter. Oncol Rep 31: 858-866, 2014.

8. Hao SH, Zhang $\mathrm{J}$ and Zhang T: A study of elemene emulsion treated advanced non small cell lung cancer on platinum based chemotherapy. Clin Focus 27: 1529-1531, 2012 (In Chinese).

9. Zhao C, Zhang YC, Sun YY, et al: A study of elemene injection combined with interventional chemotherapy treated primary liver cancer. Chin J Diffic Compl Cas 11: 882-883, 2012 (In Chinese).

10. Cheng HD, Yang Z, Zhang MJ, et al: Clinical observation of elemene combined with paclitaxel/tegafur in the treatment of advanced esophageal carcinoma. J Anhui Med Pharm 16: 1679-1681, 2012 (In Chinese).

11. Ren W and Du SK: Different effect of elemene and BCG on preventing the recurrence of postoperative superficial bladder. J Shaanxi Med 41: 1151-1152, 2012 (In Chinese).

12. Li QQ, Lee RX, Liang H, Zhong Y and Reed E: Enhancement of cisplatin-induced apoptosis by $\beta$-elemene in resistant human ovarian cancer cells. Med Oncol 30: 424-444, 2013.

13. Zhang Y, Mu XD, Li EZ, et al: The role of E3 ubiquitin ligase cbl proteins in reversing multi-drug resistance of $\beta$-elemene human gastric adenocarcinoma cells. Int J Mol Sci 14: 10075-10089, 2013.

14. Miedlich SU, Zalutskaya A, Zhu ED, et al: Phosphate-induced apoptosis of hypertrophic chondrocytes is associated with a decrease in mitochondrial membrane potential and is dependent upon Erk1/2 phosphorylation. J Biol Chem 285: 18270-18275, 2010. 
15. Hong J, Samudio I, Chintharlapalli S, et al: 1,1-bis (3'-indolyl)-1( $p$-substituted phenyl) methanes decrease mitochondrial membrane potential and induce apoptosis in endometrial and other cancer cell lines. Mol Carcinog 47: 492-507, 2008.

16. Zuo L and Motherwell MS: The impact of reactive oxygen species and genetic mitochondrial mutations in Parkinson's disease. Gene 532: 18-23, 2013.

17. Circu ML and Aw TY: Glutathione and modulation of cell apoptosis. Biochim Biophys Acta 1823: 1767-1777, 2012.

18. Park HJ, Jeon YK, You DH, et al: Daidzein causes cytochrome c-mediated apoptosis via the Bcl-2 family in human hepatic cancer cells. Food Chem Toxicol 60: 542-549, 2013.

19. Brentnall M, Rodriguez-Menocal L, De Guevara RL, et al: Caspase-9, caspase-3 and caspase-7 have distinct roles during intrinsic apoptosis. BMC Cell Biol 9: 32-40, 2013.

20. Gyulkhandanyan AV, Mutlu A, Freedman J, et al: Markers of platelet apoptosis: methodology and applications. J Thromb Thrombolysis 33: 397-411, 2012.

21. Pucci B, Kasten M and Giordano A: Cell cycle and apoptosis. Neoplasia 2: 291-299, 2000.

22. Robertson JD, Orrenius S and Zhivotovsky B: Review: nuclear events in apoptosis. J Struct Biol 129: 346-358, 2000.

23. Tait JF: Imaging of apoptosis. J Nucl Med 49: 1573-1576, 2008.

24. Radović N, Cucić S and Altarac S: Molecular aspects of apoptosis. Acta Med Croatica 62: 249-256, 2008 (In Croatian).

25. Prosperini A, Juan-García A, Font G, et al: Beauvericin-induced cytotoxicity via ROS production and mitochondrial damage in Caco-2 cells. Toxicol Lett 222: 204-211, 2013.

26. Yan F, Yang WK, Li XY, et al: A trifunctional enzyme with glutathione S-transferase, glutathione peroxidase and superoxide dismutase activity. Biochim Biophys Acta 1780: 869-872, 2008.
27. Yang L, Wang P, Wang H, et al: Fucoidan derived from Undaria pinnatifida induces apoptosis in human hepatocellular carcinoma SMMC-7721 cells via the ROS-mediated mitochondrial pathway. Mar Drugs 11: 1961-1976, 2013.

28. Liu XT, Wang YR and Zhang M: Mitochondria-mediated apoptosis: a review of recent studies. J Environ Health 30: 182-184, 2013.

29. Zhao D, Huo LF, Liu H, et al: Mitochondria, cytochrome c, caspase and cell apoptosis. J Med Pest Control 28: 1337-1340, 2012.

30. Ng KB, Bustamam A, Sukari MA, et al: Induction of selective cytotoxicity and apoptosis in human T4-lymphoblastoid cell line (CEMss) by boesenbergin a isolated from Boesenbergia rotunda rhizomes involves mitochondrial pathway, activation of caspase 3 and G2/M phase cell cycle arrest. BMC Complement Altern Med 13: 41-68, 2013

31. Ning Y, Riggins RB, Mulla JE, et al: Interferon $\gamma$ restores breast cancer sensitivity to fulvestrant by regulating STAT1, IRF1, NF- $\kappa$ B, BCL2 family members, and signaling to caspasedependent apoptosis. Mol Cancer Ther 9: 1274-1285, 2010.

32. Liang Y and Sundberg JP: SHARPIN regulates mitochondriadependent apoptosis in keratinocytes. J Dermatol Sci 63: 148-153, 2011.

33. Joshi S, Braithwaite AW, Robinson PJ and Chircop M: Dynamin inhibitors induce caspase-mediated apoptosis following cytokinesis failure in human cancer cells and this is blocked by Bcl-2 overexpression. Mol Cancer 10: 78-103, 2011.

34. Favaloro B, Allocati N, Graziano V, et al: Role of apoptosis in disease. Aging 4: 330-349, 2012.

35. Merhi F, Tang R, Piedfer M, et al: Hyperforin inhibits Akt1 kinase activity and promotes caspase-mediated apoptosis involving Bad and Noxa activation in human myeloid tumor cells. PLoS One 6: e25963, 2011 